\title{
Antiviral Activity of a Arisaema Tortuosum Leaf Extract and Some of its Constituents against Herpes Simplex Virus Type 2
}

\author{
Authors \\ Massimo Rittà ${ }^{*}$, Arianna Marengo ${ }^{2 *}$, Andrea Civra ${ }^{1}$, David Lembo ${ }^{1}$, Cecilia Cagliero ${ }^{2}$, Kamal Kant ${ }^{3}$, Uma Ranjan Lal ${ }^{3}$, \\ Patrizia Rubiolo², Manik Ghosh ${ }^{3}$, Manuela Donalisio ${ }^{1}$
}

Affiliations

1 Department of Clinical and Biological Sciences, University of Torino, Orbassano, Torino, Italy

2 Department of Drug Science and Technology, University of Torino, Torino, Italy

3 Department of Pharmaceutical Sciences \& Technology, Birla Institute of Technology, Mesra, Ranchi, India

Key words

Arisaema tortuosum, Araceae, HSV-2, antiviral activity, apigenin, luteolin

\author{
received July 18,2019 \\ revised December 19, 2019 \\ accepted December 31, 2019
}

Bibliography

DOI https://doi.org/10.1055/a-1087-8303

published online January 22, 2020 | Planta Med 2020; 86:

267-275 @ Georg Thieme Verlag KG Stuttgart · New York I

ISSN 0032-0943

\section{Correspondence}

Dr. Manuela Donalisio, PhD

Department of Clinical and Biological Sciences,

University of Torino, S. Luigi Gonzaga Hospital

Regione Gonzole, 10, Orbassano, Torino 10043, Italy

Phone: + 390116705427 , Fax: + 390119038639

manuela.donalisio@unito.it

\author{
Correspondence \\ Dr. Manik Ghosh \\ Department of Pharmaceutical Sciences \& Technology, \\ Birla Institute of Technology \\ Mesra, Ranchi, Jharkhand 835215, India \\ Phone: + 916512276247 , Fax: + 916512275401 \\ manik@bitmesra.ac.in
}

Supporting information available online at
http://www.thieme-connect.de/products

\section{ABSTRACT}

Infections caused by HSV-2 are a public health concern worldwide, and there is still a great demand for the discovery of novel anti-herpes virus agents effective against strains resistant to current antiviral agents. In this context, medicinal plants represent an alternative source of active compounds for developing efficient antiviral therapies. The aim of this study was to evaluate the antiviral activity of Arisaema tortuosum, a plant used in the traditional medicine of India. A chloroform soluble fraction of the leaves exhibited anti-HSV2 activity with a selectivity index of 758 . The extract was also active against acyclovir-resistant HSV-2 and HSV-1. The mechanism of action of the extract was investigated evidencing inhibition of both early and late events of the HSV-2 replicative cycle. A HPLC-PDA-MS/MS analysis showed the presence of flavonoids including apigenin and luteolin in the chloroform extract (CE). Apigenin and luteolin showed a high inhibitory activity with $\mathrm{EC}_{50}$ values of 0.05 and $0.41 \mu \mathrm{g} / \mathrm{mL}$, respectively. Both compounds exhibited antiviral activity when added up to $6 \mathrm{~h}$ post infection and were able to reduce the viral progeny production. In addition, apigenin interfered with cell-to-cell virus spread.

\section{Introduction}

Herpes simplex virus type 2 (HSV-2) is among the most prevalent sexually transmitted viruses. The Centers for Disease Control and Prevention (CDC) estimates that, annually, 776,000 people in the United States get new genital herpes infections, and more than 1 out of every 6 people aged 14 to 49 y have genital herpes [1]. Most HSV-2 infections are subclinical, but even without signs of the disease, herpes can still be spread to sex partners. Clinical manifestations are characterized by recurrent, painful lesions, named herpes sores, usually appearing on or around the genitals, rectum, or mouth. Genital herpes may cause painful genital ulcers that can be severe and persistent in immune suppressed people,

* These authors contributed equally to this work. 


$\begin{array}{ll}\text { ABBREVIATIONS } \\ \text { ADME-T } & \begin{array}{l}\text { absorption, distribution, metabolism, } \\ \text { excretion and toxicity }\end{array} \\ \text { AE } & \begin{array}{l}\text { aqueous extract } \\ \text { BE }\end{array} \\ \text { CE-butanol extract } \\ \text { EaE } & \text { chloroform extract } \\ \text { EE } & \text { ethyl acetate extract } \\ \text { ESI } & \text { ethanolic extract } \\ \text { HE } & \text { electrospray ionization } \\ \text { HSV-1 } & \text { herpes simplex virus type 1 } \\ \text { HSV-2 } & \text { HSV type 2 } \\ \text { HSV-2 } & \text { ACV-r HSV-2 strain with phenotypic resistance } \\ & \text { to acyclovir } \\ \text { MOI } & \text { multiplicity of infection } \\ \text { MTS } & \text { [3-(4,5-dimethylthiazol-2-yl)-5-(3-carboxyme- } \\ & \text { thoxyphenyl)- 2-(4-sulfophenyl)-2H-tetrazolium] } \\ \text { PFU } & \text { plaque-forming units } \\ \text { PIS } & \text { product ion scan } \\ \text { SI } & \text { selectivity index } \\ \text { SIM } & \text { selective ion monitoring } \\ \text { SRM } & \text { selected reaction monitoring } \\ & \end{array}$

such as HIV-infected persons. Recurrent outbreaks of genital herpes are common during an individual's lifespan, since, after the primary infection, HSV-2 establishes a latency in the neurons of the sensory ganglia and it can be reactivated by several stimuli including immunosuppression, stress, and hormonal changes [2]. There is currently no cure or a commercially available vaccine for genital herpes. Antiviral medications, like acyclovir, valacyclovir, and famciclovir, can reduce the severity, shorten outbreaks, and decrease the rate of transmission to partners [3]. However, these synthetic nucleoside analogues are unable to suppress the latent infection, and their wide use favors the selection of drug-resistant HSV mutants. Genital herpes can be associated with resistance to available drugs especially in immunocompromised patients as result of extended viral replication and the reduced elimination of resistant strains [4]. Furthermore, acyclovir, the drug of choice for treating HSV infections, is characterized by a short half-life and incomplete absorption; therefore, it must be taken repeatedly throughout the day [5]. These drawbacks of available drugs prompt the discovery and development of novel anti-HSV-2 agents acting with a different mechanism of action than acyclovir and its derivatives, which are inhibitors of viral DNA replication, in order to improve the efficacy and pharmacokinetics of actual treatments. It is widely accepted that medicinal plants are rich sources of alternative molecules with large structural diversity and complexity for the treatment of infectious disorders. Natural products have been explored as HSV-2 inhibitors, which may be useful for the development of new drugs and act through different mechanisms of antiviral action [6,7].

Arisaema tortuosum (Wall.) Schott, known as whipcord cobra lily, is a monocotyledon plant belonging to the Araceae family. It is characterized by a whip-like spadix arising from its "jack-in-the- pulpit" flower and grows to $30 \mathrm{~cm}$ in height [8]. This plant is widespread in rhododendron forest and alpine meadows in the Himalayas, Southern India, Myanmar, and Western China and even at elevations of 1500-2200 meters in Nepal $[9,10]$. The plant tuber (dried powder and juice) has been used in traditional medicine of India for its therapeutic properties for piles, ailments related to digestive tract (constipation, indigestion, abdominal pain, and dysentery), rheumatism, snake bites, and in treating bone fracture and parasitic infections [11-13]. The tuber extract has shown antioxidant, anti-inflammatory, and antiproliferative activities; recently, $n$-hexane, chloroform, and ethyl acetate fractions of $A$. tortuosum have been investigated for their antibacterial and antifungal activities [14]. Previous works on A. tortuosum revealed the presence of flavonoids and lectins $[9,10]$. Among the protein components, lectins purified from $A$. tortuosum tubers exerted in vitro antiproliferative activity against human cancer cell lines and anti-insect activity $[9,10,15]$. Recently, merged molecular docking, ADME-T, and dynamics approaches identified several A. tortuosum phytoconstituents as potential inhibitors of HSV-1 and HSV-2 enzymes, namely thymidine kinase and serine protease [16]. In this context, according to the need to continue searching for novel antiviral agents, this study was undertaken to explore whether $A$. tortuosum leaves and tubers extracts and their identified pure compounds, for which a commercial standard was available, exerted an effective antiviral activity against HSV-2 and ACV-r HSV-2 strains in vitro. Furthermore, their mode of antiviral action was investigated at different steps of the viral infection cycle.

\section{Results and Discussion}

This study investigated the antiviral activity of $A$. tortuosum extracts against HSV-2 infection in vitro on Vero cells. Firstly, ethanolic extracts (EE) of both leaves and tubers were prepared, and their effect on cellular viability was evaluated. Cell viability assays were performed on uninfected Vero cells, treated with 3 different concentrations $(100,10,1 \mu \mathrm{g} / \mathrm{mL})$. Since extracts were dissolved in DMSO, control wells were prepared by treating cells with equal volumes of DMSO. As shown in > Fig. $\mathbf{1}$ a, total toxicity was evident at the highest concentration for both samples. On the other hand, partial toxicity was observed at $10 \mu \mathrm{g} / \mathrm{mL}$ for the tuber EE, while no toxic effect was detected for the leaf EE. Both extracts exhibited no toxicity at the lowest tested concentration. Based on these results, the EE of the leaves, which exhibit a lower toxicity compared to the tubers extract, was further fractionated using solvents of increasing polarity ( $n$-hexane, chloroform, ethyl acetate, $n$-butanol). The extracts and the remaining aqueous fraction (AE) were submitted to viability assays. As reported in > Fig. $\mathbf{1}$ b, the $n$-hexane $(\mathrm{HE})$, ethyl acetate (EaE), and $n$-butanol (BE) extracts resulted highly toxic, whereas the chloroform extract (CE) and the AE did not have negative effects on cell viability at any tested concentrations. The nontoxic fractions from the leaves were selected to investigate their potential inhibitory activity against herpetic infections.

The antiviral assay was performed by treating cells in presence of decreasing concentrations of extracts before, during, and after viral infection in order to generate dose-response curves. Results 

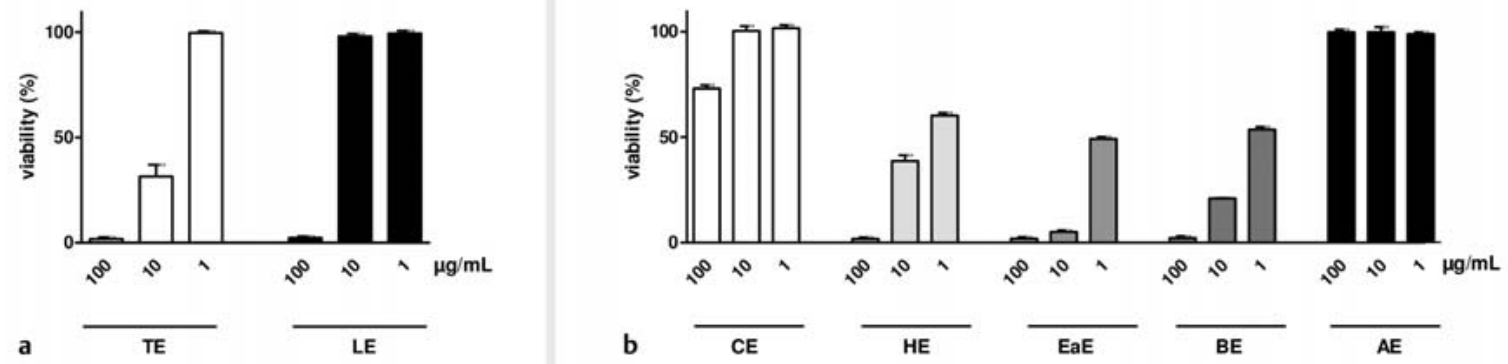

- Fig. 1 Cell viability assays. Panel a: Evaluation of the effect of tuber (TE) and leaves (LE) EEs from A. tortuosum on Vero cells viability. Panel b: Evaluation of the effect of CE, $n$-hexane (HE), ethyl acetate (EaE), $n$-butanol (BE) fractions, and the remaining AE from LE on cellular viability. Data are reported as percentages of viable cells as determined by MTS assay for 100,10 , and $1 \mu \mathrm{g} / \mathrm{mL}$ concentrations. Three independent experiments were performed $(n=6)$.

- Table 1 Antiviral activity of $A$. tortuosum extracts.

\begin{tabular}{|c|c|c|c|c|}
\hline & Virus & $\mathrm{EC}_{50}{ }^{\mathrm{a}}(\mu \mathrm{g} / \mathrm{mL})\left(95 \% \mathrm{Cl}^{\mathrm{b}}\right)$ & $\mathrm{CC}_{50} \mathrm{c}(\mu \mathrm{g} / \mathrm{mL})$ & $\mathrm{SI}^{\mathrm{d}}$ \\
\hline \multirow[t]{3}{*}{ CE leaves } & HSV-2 & $0.53(0.41-0.69)$ & 402 & 758 \\
\hline & HSV-1 & $2.64(0.74-9.37)$ & 31.8 & 12 \\
\hline & HSV-2 ACV-r ${ }^{\mathrm{e}}$ & $0.86(0.69-1.06)$ & 402 & 467.4 \\
\hline \multirow[t]{3}{*}{ AE leaves } & HSV-2 & n. a. ${ }^{f}$ & 1852 & n.a. \\
\hline & HSV-1 & n.a. & n.a. & n.a. \\
\hline & HSV-2 ACV-r & n.a. & 1852 & п.а. \\
\hline
\end{tabular}

${ }^{\mathrm{a}} \mathrm{EC}_{50}$ : half maximal effective concentration, ${ }^{\mathrm{b}} \mathrm{Cl}$ : confidence interval, ${ }^{\mathrm{C}} \mathrm{CC}_{50}$ : half maximal cytotoxic concentration, ${ }^{\mathrm{d}} \mathrm{Sl}$ : selectivity index, ${ }^{\mathrm{e}} \mathrm{HSV}-2 \mathrm{ACV}-\mathrm{r}$ : acyclovir resistant $\mathrm{HSV}-2$ strain, ${ }^{\mathrm{f}} \mathrm{n}$. a.: not assessable

of the viral plaque reduction assays showed that the CE from the leaves was endowed with anti-HSV-2 activity with $\mathrm{EC}_{50}$ value of $0.53 \mu \mathrm{g} / \mathrm{mL}$ ( $\vee$ Table 1 ). The antiviral activity of CE was not a consequence of a cytotoxic effect since the active fraction showed a favorable SI value of 758. By contrast, no significant antiviral activity was reported for $\mathrm{AE}$ at any concentrations tested. Of note, $\mathrm{CE}$ exerted an inhibitory effect also against HSV-1, although with higher $\mathrm{EC}_{50}$ than against HSV-2, indicating a broad spectrum of activity against herpes viruses. Given the emerging appearance of resistant viral strains to available drugs, the activity of $\mathrm{CE}$ against an HSV-2 ACV-r was assessed. Interestingly, the extract inhibited HSV-2 ACV-r infection with an $\mathrm{EC}_{50}$ value of $0.86 \mu \mathrm{g} / \mathrm{mL}$ ( $\vee$ Table 1). These data suggested that the mode of antiviral action of the investigated fraction differs from that of acyclovir.

In order to identify the major mechanism of action, the CE was subjected to further studies. First, a virus inactivation assay was performed to explore whether the extract directly inactivates HSV-2 particles. To this end, the virus was incubated with a high concentration of extract that reduces virus infection almost completely at $37^{\circ} \mathrm{C}$ for 0 or $2 \mathrm{~h}$ and at $4{ }^{\circ} \mathrm{C}$ for $2 \mathrm{~h}$, and then the viral titer was measured at dilutions corresponding to concentrations that are not antiviral when added on cells. Results depicted in - Fig. 2 demonstrate that CE did not inactivate significantly the virus particles at any incubation conditions tested. Therefore, we

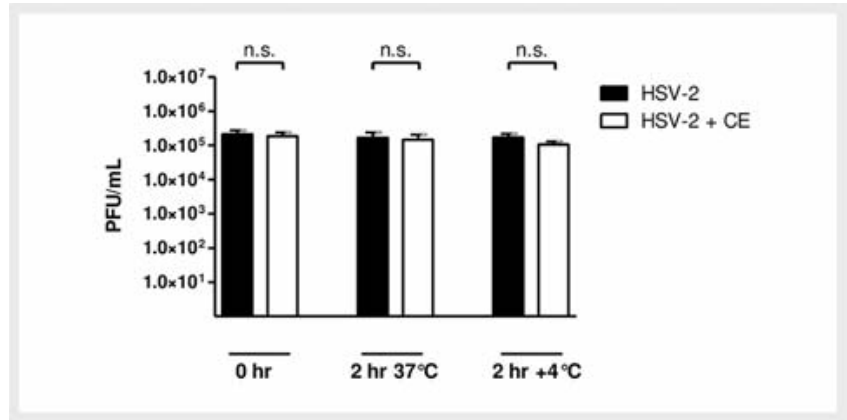

- Fig. 2 Evaluation of inactivation of HSV-2 particles by A. tortuosum $\mathrm{CE}$ at $37^{\circ} \mathrm{C}$ for 0 or $2 \mathrm{~h}$, and at $4^{\circ} \mathrm{C}$ for $2 \mathrm{~h}$. On y-axis, the infectious titers are expressed as PFU per $\mathrm{mL}$. Error bars represent standard error of the mean for 3 independent experiments. $(n=6)$.

investigated if the active extract targets cell surface or intracellular events involved in essential steps of the viral replicative cycles. To explore this hypothesis, time of addition assays were performed by treating cells with serial dilutions of the extract $2 \mathrm{~h}$ before infection or during infection or post-infection. As shown in

- Fig. 3 (panel A), CE did not exhibit anti-HSV-2 activity when Vero cells were pretreated with scalar doses of the fraction prior 




- Fig. 3 Investigation of mechanism of action of A. tortuosum CE on replicative cycle of HSV-2. Panel a: Time of addition assays for the extract. Panel b: Attachment and entry assay for the extract. Error bars represent the standard error of the mean for 3 independent experiments. ( $n=6$ ).

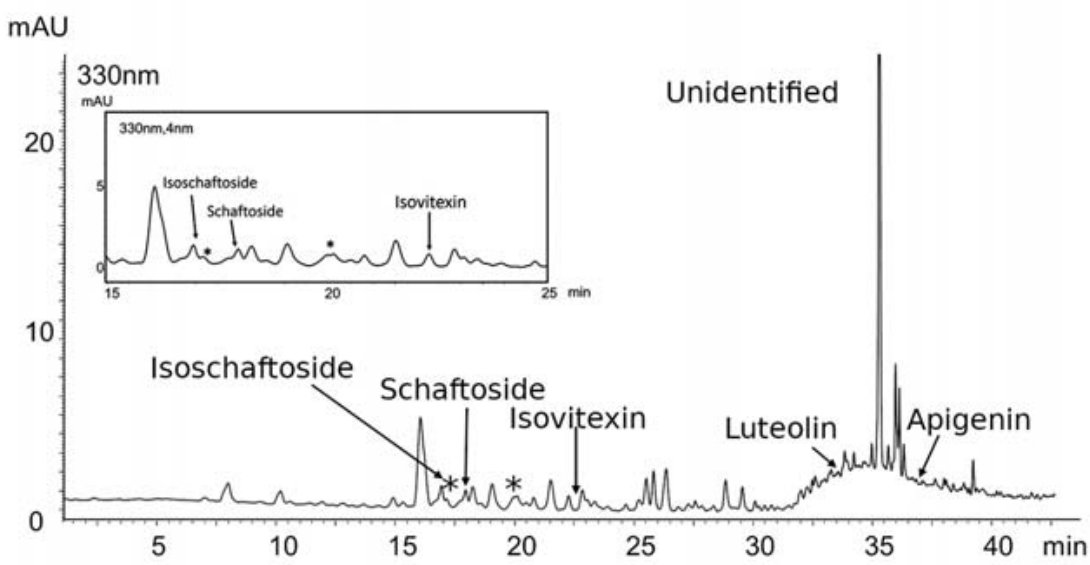

- Fig. 4 HPLC-PDA representative profile $(\lambda=330 \mathrm{~nm})$ of the CE of the leaves of $A$. tortuosum. $\left({ }^{*}\right)$ indicates the tentative identification of apigenin $C$-hexoside-C-pentoside $(\mathrm{MW}=564)$ isomers.

to viral infection excluding a stable interaction of the extract with cellular components. Treatment for $2 \mathrm{~h}$ concomitant to HSV-2 infection showed that $C E$ exerted net antiviral activity with an $\mathrm{EC}_{50}$ value of $0.77 \mu \mathrm{g} / \mathrm{mL}$. These data suggest a probable activity of CE on the early steps of HSV-2 infection. Having excluded the viral particle as a target of the antiviral activity, more stringent tests (i.e., the attachment and entry assays) were performed to assess if the putative target of CE was the virus-cell interactions. This hypothesis was confirmed as reported in $\mathbf{F i g . 3} \mathbf{b}$ : CE inhibited both the viral attachment and entry in the cell generating doseresponse curves with $\mathrm{EC}_{50}$ values of 2.17 and $6.69 \mu \mathrm{g} / \mathrm{mL}$, respectively. When it was added to cells immediately after the HSV-2 infection, CE showed relevant anti-HSV-2 activity, with an $\mathrm{EC}_{50}$ value of $4.75 \mu \mathrm{g} / \mathrm{mL}$ ( $\vee$ Fig. 3 a), indicating that later steps of the virus replicative cycle are inhibited. Taken together, the results evidenced that CE exerts its antiviral activity by inhibiting both early and late events of the HSV-2 replicative cycle.

The phytochemical composition of the CE of $A$. tortuosum leaves was investigated through HPLC-PDA-MS/MS ( $\vee$ Fig. 4). Several flavonoids, in particular luteolin and apigenin derivatives, were detected. Identification was based on the UV, MS, and MS/ MS spectral information and comparison to authentic standards, when available, or to literature data ( $\bullet$ Table 2 ). When a corre- spondence between the positive and negative pseudo molecular ions in $\mathrm{ESI}^{+}$and $\mathrm{ESI}^{-}$was present, a product ion scan analysis (PIS) of the pseudo molecular ions (in both $\mathrm{ESI}^{+}$and $\mathrm{ESI}^{-}$modes) was performed, providing diagnostic fragments for each molecule. Isoschaftoside, schaftoside, isovitexin, luteolin, and apigenin were confirmed by the co-injection of the corresponding authentic standards, while other peaks were tentatively assigned as apigenin C-hexoside-C-pentoside isomers, apigenin C-dihexoside, and luteolin/kaempferol O-hexoside, based on the UV, MS, and MS/MS spectral information $[17,18]$. As an example, the UV maximum absorptions at $330 / 271 \mathrm{~nm}$, the molecular weight of 564, and the fragments obtained in the PIS analysis, similar to those of isoschaftoside and schaftoside standards, support the tentative identification of apigenin $C$-hexoside- $C$-pentoside isomers $(\triangleright \mathrm{Ta}$ ble 2). A main unidentified peak with a UV maximum absorption at $313 \mathrm{~nm}$ and a molecular weight of 308 amu was detected. The UV and MS spectra together with the PIS analysis of the positive ( $\mathrm{m} / \mathrm{z} 309)$ and negative ( $\mathrm{m} / \mathrm{z} 307)$ pseudomolecular ions are provided as supporting information (Fig. 1S, Supporting Information). The presence of apigenin C-glycoside derivatives, in particular schaftoside and isoschaftoside, had been previously reported in Arisaema species [19]. 
- Table 2 List of identified and putatively-identified compounds in A. tortuosum extracts.

\begin{tabular}{|c|c|c|c|c|}
\hline Compound & UV max & MW & PIS ESI ${ }^{+}$ & $\mathrm{PIS} \cdot \mathrm{ESI}^{-}$ \\
\hline $\begin{array}{l}\text { Isochaftoside* (apigenin 6-C- } \\
\text { arabinosyl-8-C-glucoside) }\end{array}$ & $333 / 271$ & 564 & $427 / 391 / 349 / 325 / 295$ & $473 / 443 / 383 / 353$ \\
\hline $\begin{array}{l}\text { Schaftoside* (apigenin 6-C- } \\
\text { glucosyl-8-C-arabinoside) }\end{array}$ & $337 / 271$ & 564 & $469 / 433 / 397 / 379 / 349 / 325 / 295$ & $473 / 443 / 412 / 383 / 353 / 323$ \\
\hline Apigenin C-hexoside-C-pentoside & $330 / 271$ & 564 & $445 / 379 / 325 / 391 / 295$ & $473 / 383 / 353$ \\
\hline Luteolin/kaempferol O-hexoside & $267 / 330$ & 448 & 287 & 285 \\
\hline Isovitexin*(apigenin 6-C-glucoside) & $330 / 271$ & 432 & $313 / 309 / 295 / 283$ & $341 / 309 / 294 / 283 / 280.8 / 194 / 121$ \\
\hline Luteolin* & $349 / 252 / 266$ & 286 & $153 / 133 / 117$ & $151 / 133 / 107$ \\
\hline Unidentified & 313 & 308 & $309: 166 / 145 / 117 / 107$ & $307: 215 / 197 / 169 / 121$ \\
\hline Apigenin* & $337 / 266$ & 270 & $163 / 153 / 121 / 119$ & $156 / 117$ \\
\hline
\end{tabular}

- Table 3 Antiviral activity of constituents from A. tortuosum.

\begin{tabular}{|c|c|c|c|c|}
\hline Constituents & Virus & $\mathrm{EC}_{50}{ }^{\mathrm{a}}(\mu \mathrm{g} / \mathrm{mL})\left(95 \% \mathrm{Cl}^{\mathrm{b}}\right)$ & $\mathrm{CC}_{50}{ }^{\mathrm{c}}(\mu \mathrm{g} / \mathrm{mL})$ & $\mathrm{SI}^{\mathrm{d}}$ \\
\hline \multirow[t]{3}{*}{ Isoschaftoside } & HSV-2 & $>33$ & $>33$ & $>1$ \\
\hline & HSV-1 & $>33$ & $>33$ & $>1$ \\
\hline & HSV-2 ACV-re & $>33$ & $>33$ & $>1$ \\
\hline \multirow[t]{3}{*}{ Schaftoside } & HSV-2 & $>33$ & $>33$ & $>1$ \\
\hline & HSV-1 & $>33$ & $>33$ & $>1$ \\
\hline & HSV-2 ACV-r & $>33$ & $>33$ & $>1$ \\
\hline \multirow[t]{3}{*}{ Isovitexin } & HSV-2 & $>33$ & $>33$ & $>1$ \\
\hline & HSV-1 & $>33$ & $>33$ & $>1$ \\
\hline & HSV-2 ACV-r & $>33$ & $>33$ & $>1$ \\
\hline \multirow[t]{3}{*}{ Apigenin } & HSV-2 & $0.05(0.03-0.07)$ & 5.12 & 102.4 \\
\hline & HSV-1 & $7.04(0.61-81.1)$ & 12.9 & 1.8 \\
\hline & HSV-2 ACV-r & $2.33(1.65-3.29)$ & 5.12 & 2.1 \\
\hline \multirow[t]{3}{*}{ Luteolin } & HSV-2 & $0.41(0.35-0.45)$ & 7.35 & 17.9 \\
\hline & $\mathrm{HSV}-1$ & n.a. ${ }^{f}$ & n.a. & n.a. \\
\hline & HSV-2 ACV-r & $1.55(0.89-2.67)$ & 7.35 & 4.7 \\
\hline \multirow[t]{3}{*}{ Acyclovirg } & HSV-2 & $0.1(0.07-0.27)$ & $>33$ & $>330$ \\
\hline & $\mathrm{HSV}-1$ & n.a. & n.a. & n.a. \\
\hline & HSV-2 ACV-r & $>33$ & $>33$ & $>1$ \\
\hline
\end{tabular}

${ }^{\mathrm{a}} \mathrm{EC}_{50}$ : half maximal effective concentration, ${ }^{\mathrm{b}} \mathrm{Cl}$ : confidence interval, ${ }^{\mathrm{C}} \mathrm{CC}_{50}$ : half maximal cytotoxic concentration, ${ }^{\mathrm{d}} \mathrm{SI}$ : selectivity index, ${ }^{\mathrm{e}} \mathrm{HSV}-2 \mathrm{ACV}-\mathrm{r}$ : acyclovir resistant HSV-2 strain, ${ }^{f}$ n. a.: not assessable, ${ }^{9}$ acyclovir was used as positive control

Commercially available standards of those components identified in the extracts as isoschaftoside, schaftoside, isovitexin, apigenin, and luteolin were tested for their antiviral activity against HSV-2 infection. Among them, the apigenin C-glycosides isoschaftoside, schaftoside, and isovitexin did not exert a significant antiviral activity against HSV-2 infection ( $\vee$ Table 3). Conversely, apigenin and luteolin showed a high inhibitory activity with an $\mathrm{EC}_{50}$ of 0.05 and $0.41 \mathrm{\mu g} / \mathrm{mL}$, respectively, which confirmed the anti-HSV-2 effect reported in literature, although we observed a more favorable SI of apigenin with a value of 102.4 than that re- ported by Chiang et al. and Visintini et al. [20-23]. — Table 3 showed that apigenin was active not only against HSV-2 but also against HSV-1 $\left(\mathrm{EC}_{50}, 7.04 \mu \mathrm{g} / \mathrm{mL}\right)$. By contrast, although luteolin has been identified as a promising inhibitor of HSV-1 using in silico approaches [16], no anti-HSV-1 activity was observed in cellbased assay here reported. Interestingly, the HSV-2 ACV-r strain's infectivity was inhibited by apigenin and luteolin with $\mathrm{EC}_{50}$ values of 2.33 and $1.55 \mu \mathrm{g} / \mathrm{mL}$, respectively. According to literature, the mode of antiviral action of apigenin has never been investigated, whereas a study reported the modulation of the NF-KB signaling 


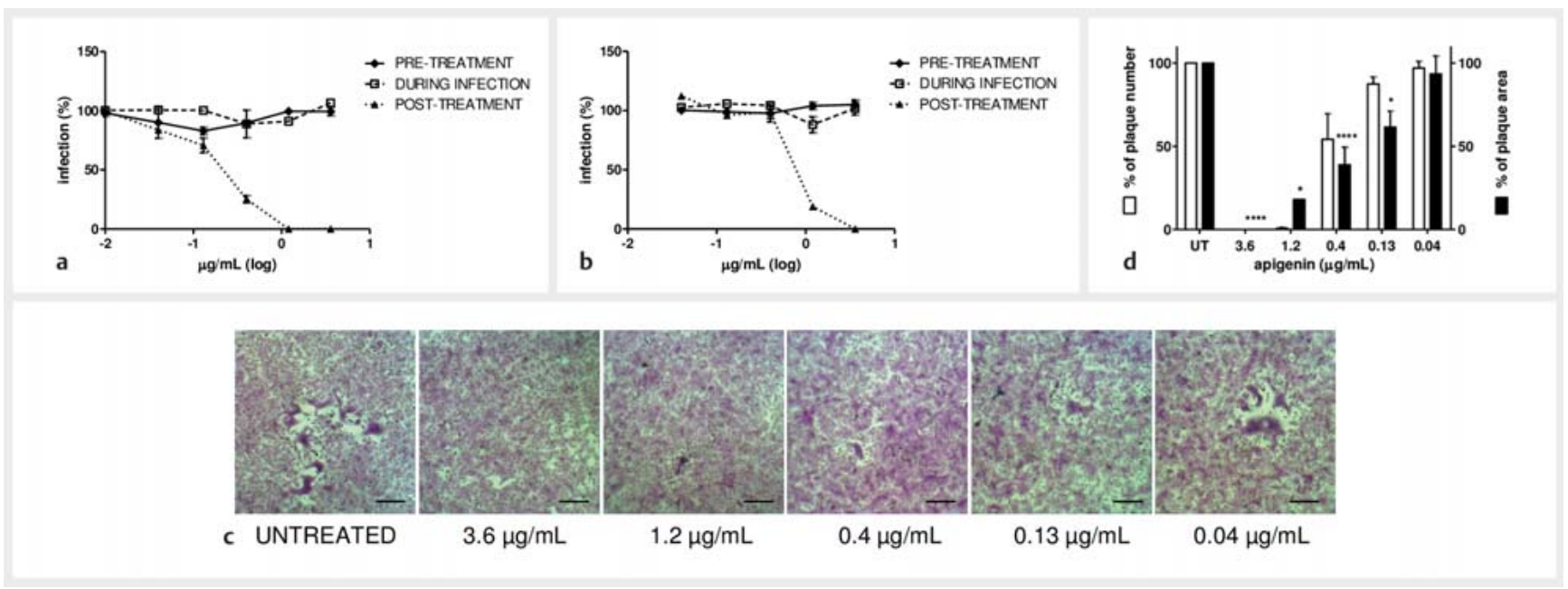

- Fig. 5 Time of addition assays for apigenin and luteolin. Vero cells were treated with apigenin (panel a) or luteolin (panel b) prior to HSV-2 infection (pre-treatment), during the infection period (during infection), or after the infection (post-treatment). Error bars represent the standard error of the mean for 3 independent experiments. $(n=6)$. Panel c: Representative HSV-2 plaques in Vero cells are reported according to the concentrations of apigenin in the post-treatment assay. Scale bar, $150 \mu \mathrm{m}$. Panel d: The histograms show the percentage of HSV-2 plaque areas (black) and plaque numbers (white) of treated wells in comparison to that of untreated wells as a function of the concentration of apigenin in the posttreatment assay. The pictures and histograms reported are representative of $\geq 10$ plaques per condition. ${ }^{*} \mathrm{p}<0.05 ;{ }^{* * * *} \mathrm{p}<0.0001$, as compared to the untreated by one-way analysis of variance. UT, untreated.

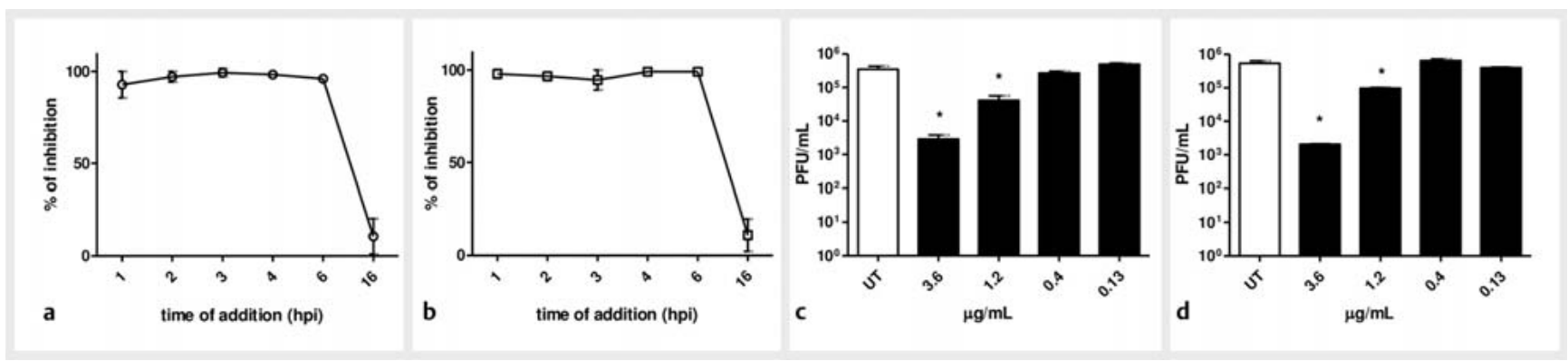

- Fig. 6 Post entry assays for apigenin and luteolin. Vero cells were treated with apigenin (panel a) or luteolin (panel b) at $\mathrm{EC}_{90}$ concentrations at 1 , 2, 3, 4, 6, 16 h post HSV-2 infection (hpi). Data are reported as percentages of HSV-2 plaques in comparison to control. Error bars represent the standard error of the mean for 3 independent experiments. $(n=6)$. Effects of apigenin (panel c) and luteolin (panel d) on multiple cycles of HSV-2 replication by yield reduction assay. Viral titers are expressed as $\mathrm{PFU} / \mathrm{mL}$ and shown as mean \pm standard error for 3 independent experiments. ${ }^{*} \mathrm{p}<0.05$ as compared to the untreated (UT) by one-way analysis of variance.

pathway by luteolin in infected cells [23]. We therefore explored which steps of HSV-2 replicative cycle were inhibited by these 2 active compounds and their contribution to the anti-HSV-2 activity of the CE of $A$. tortuosum leaves. Virucidal assays demonstrated that both apigenin and luteolin did not inactivate the virus particles (Fig. 2S, Supporting Information) and showed inhibition (EC 500.408 and $0.246 \mu \mathrm{g} / \mathrm{mL}$, respectively) only when added to the cells after virus inoculum in time-of-addition assays ( $\vee$ Fig. $\mathbf{5 a , b}$ ). The absence of inhibitory activity by treating cells with compounds before infection or during infection excludes a probable activity on the early steps of HSV-2 infection. To substantiate this interpretation, we demonstrated by specific assays that apigenin and luteolin did not inhibit the attachment of the virus to the cell surface and the entry in Vero cells (Fig. 3S, Sup- porting Information). By contrast, Ojha et al. evidenced that luteolin isolated from Pedilanthus tithymaloides exerted inhibitory effect when the drug was added $2 \mathrm{~h}$ prior to infection [23]. Our results of time of addition assays indicated that both compounds affect late steps of the replicative cycle of HSV-2. Furthermore, when apigenin was added on cells after infection, not only a dose response reduction of viral plaques was observed, but also the area of the remaining plaques decreased in a dose-dependent manner ( $\vee$ Fig. $\mathbf{5 c}, \mathbf{d}$ ), suggesting that apigenin interferes with cell-to-cell virus spreading. Moreover, we tested the inhibitory activity of apigenin and luteolin by viral plaque reduction assays when they were added to the cells at different time points, from 1 to $16 \mathrm{~h}$ after removal of the virus ( $>$ Fig. $\mathbf{6 a}$ a, b, respectively). Interestingly, we observed that around $90 \%$ inhibitory activity was 
still present $6 \mathrm{~h}$ post-infection at the $\mathrm{EC}_{90}$ concentration tested of both compounds. To evaluate whether the apigenin and luteolin treatment lead to a decrease in viral progeny production, post entry assays measuring the virus yield were performed. Under these experimental conditions, the 2 pure compounds significantly reduced HSV-2 titers at high tested concentrations (3.6 and $1.2 \mathrm{\mu g} / \mathrm{mL}$ ) as expression of their ability to inhibit multiple cycles of viral replication and limit the production of infectious virus particles ( $\bullet$ Fig. 6 c, d).

Taken together, our data indicate that apigenin and luteolin exert an inhibitory effect on post entry steps of the virus replicative cycle, suggesting a contribution to the A. tortuosum CE antiviral activity against the late steps of HSV-2 replication. The 2 compounds were quantified in the extract by HPLC-MS/MS, by applying 2 acquisition methods (SRM, SIM) to confirm the accuracy of the obtained data. Quantification was expressed as the mean of the results obtained in both acquisition methods (RSD\% of 12\%) and showed similar apigenin and luteolin contents in the extract $(0.025 \mu \mathrm{g} / \mathrm{mg} \pm 0.003$ and $0.026 \mu \mathrm{g} / \mathrm{mg} \pm 0.003$ for apigenin and luteolin respectively; $n=3$ ). Although apigenin's and luteolin's structures differ only in the presence of the 3 '-OH, a higher inhibitory activity of apigenin compared to luteolin was observed against HSV-2 ( $\triangleright$ Table 3 ). In this context, the higher hydrophobicity of apigenin $(\log P 3.07)$ compared to luteolin $(\log P 2.73)$ and, consequently, the expected greater ability of crossing the cell membrane should be pointed out. It is noteworthy that none of the tested pure apigenin C-glycosides were active. Apigenin and luteolin are minor constituents of the CE and may not account alone for the antiviral activity of the extract. Therefore, further studies will be required to investigate the antiviral role of other components of $A$. tortuosum CE involved in the inhibition of early events of the HSV-2 infection.

Overall, this study reports for the first time an inhibitory activity of $A$. tortuosum leaves extract against a viral infection, in particular against herpetic infections. Among the detected components, apigenin is an interesting candidate given its antiviral activity and its ability to prevent cell-to-cell virus spread and to reduce the viral progeny production. These promising results should prompt in vivo studies to further assess its potential for the treatment of HSV-2 infection.

\section{Materials and Methods}

\section{Chemicals}

Acyclovir, used as a positive control for HSV-2 antiviral activity, acetonitrile (LC-MS grade), formic acid ( $\geq 98 \%$ HPLC purity), and apigenin ( $\geq 99 \%$ HPLC purity) were purchased from Sigma-Aldrich. Luteolin ( $\geq 99 \%$ HPLC purity), isovitexin ( $\geq 99 \%$ HPLC purity), schaftoside ( $\geq 90 \%$ HPLC purity), and isoschaftoside ( $\geq 95 \%$ HPLC purity) were from Extrasynthese. Deionized water (18.2 M $\Omega$ $\mathrm{cm}$ ) was obtained from a Milli-Q purification system (Millipore).

\section{Plant material}

Leaves and tubers of $A$. tortuosum were collected in Bagsiad Village $(31.561,77.123)$, Mandi, Himachal Pradesh, India, in August and September 2016. A specimen was authenticated at Raw
Materials Herbarium \& Museum, Delhi (RMHD) CSIR-NISCAIR, India. Voucher specimens were deposited at the herbarium (NISCAIR/RHMD/Consult/2013/-2249/30). The plant parts were cleaned, shade dried, and properly grounded to coarse powder.

\section{Extracts preparation}

Powdered leaves and tubers ( $1 \mathrm{~kg}$ each) were extracted with ethanol: water $(95: 5, \mathrm{v} / \mathrm{v})$ with a $1: 10$ ratio of herbal substance to extraction solvent. The ethanol solutions were combined and dried in a rotary evaporator at $40 \pm 5^{\circ} \mathrm{C}$ to provide the crude extracts (77 and $68 \mathrm{~g}$ for the leaves and tubers, respectively). The EE from the leaves was further partitioned using different solvents to yield the HE (26g), CE (17.4g), EaE (9.2 g), and BE (12 g) extracts (Fig. 4S, Supporting Information). The extracts were then lyophilized and kept in the dark at $+4{ }^{\circ} \mathrm{C}$ until further use. For the viability and antiviral assays, the extracts were dissolved in DMSO (except for the AE fractions, which were dissolved in water) to a final concentration of $25 \mathrm{mg} / \mathrm{mL}$, and used as the stock solutions.

\section{Phytochemical analysis}

For HPLC-PDA-MS/MS analysis, a $10 \mathrm{mg} / \mathrm{mL}$ stock solution of the leaf CE was prepared in acetone $100 \%$. A $2.5 \mathrm{mg} / \mathrm{mL}$ working solution was then prepared in methanol: $\mathrm{H}_{2} \mathrm{O} 50: 50$, filtered through a $13 \mathrm{~mm}$ diameter, $0.22 \mu \mathrm{m}$ pore diameter, hydrophilic PTFE syringe filter, and subjected to HPLC-PDA-MS/MS analysis. The working solution $(5 \mu \mathrm{L})$ was analyzed in duplicate on a Shimadzu Nexera X2 system equipped with a photodiode array detector SPD-M20A and coupled in series to a triple quadruple Shimadzu LCMS-8040 system with ESI source. The separation was performed with an Ascentis Express RP-Amide column $(10 \mathrm{~cm} \times 2.1 \mathrm{~mm}, 2.7 \mu \mathrm{m}$, Supelco) using water (A) and acetonitrile (B) both containing $0.1 \%$ formic acid as mobile phase. The flow rate was $0.4 \mathrm{~mL} / \mathrm{min}$, and the column temperature was maintained at $30^{\circ} \mathrm{C}$. The gradient program was as follows: $5 \% \mathrm{~B}$ for $3 \mathrm{~min}, 5-15 \% \mathrm{~B}$ in $17 \mathrm{~min}, 15-25 \% \mathrm{~B}$ in $10 \mathrm{~min}, 25-75 \% \mathrm{~B}$ in $12 \mathrm{~min}, 75-100 \%$ B in $10 \mathrm{~min}, 100 \%$ B for $1 \mathrm{~min}$. The total separation time including pre-run and post-run was $60 \mathrm{~min}$. UV spectra were acquired over the $220-450 \mathrm{~nm}$ wavelength range. MS operative conditions were as follows: heat block temperature: $200^{\circ} \mathrm{C}$; desolvation line $(\mathrm{DL})$ temperature: $250^{\circ} \mathrm{C}$; nebulizer gas flow rate: $3 \mathrm{~L} / \mathrm{min}$; drying gas flow rate: $15 \mathrm{~L} / \mathrm{min}$. Mass spectra were acquired both in positive and in negative full-scan mode over the range $100-1000 \mathrm{~m} / \mathrm{z}$, event time $0.5 \mathrm{~s}$. PIS mode (collision energy: - 35.0 V for ESI+ and 35.0 V for ESI-, event time: $0.2 \mathrm{~s}$ ) was applied to compounds for which a correspondence between the pseudomolecular ions $[\mathrm{M}+\mathrm{H}]+$ in $\mathrm{ESI}+$ and $[\mathrm{M}-\mathrm{H}]-$ in ESI- was confirmed. Luteolin and apigenin were quantified in the extract through SRM acquisition in ESI- (collision energy: $35.0 \mathrm{~V}$, dwell time: $5 \mathrm{msec}$ ) on specific ion products derived from precursor ion fragmentation and SIM acquisition (dwell time: $5 \mathrm{msec}$ ) of precursor ions. The transitions and the ions selected, based on the PIS analysis of each standard, were as follows: apigenin (SRM: $\mathrm{m} / \mathrm{z}$ $269 \rightarrow$ 117; SIM: m/z 269), luteolin (SRM: m/z $285 \rightarrow$ 133; SIM: $m$ / $z$ 285) (Fig. 5S, Supporting Information). The calibration curves were prepared with 5 different concentrations in the range of $0.001-0.5 \mu \mathrm{g} / \mathrm{mL}$ and with 4 different concentrations in the range of $0.01-0.5 \mu \mathrm{g} / \mathrm{mL}$ for the SRM and SIM acquisition mode, respec- 
tively. The calibration curve equations were as follows: apigenin SRM: $\quad y=1277518.75 x+6432.02, \quad$ R2 $=0.9996 ; \quad$ SIM: $\quad y=$ $11702570.51 x+89688.49, \quad R 2=0.9998 ;$ luteolin SRM: $y=$ $1143071.98 x+3815.38, R 2=0.9996 ;$ SIM: $y=12392796.81 x+$ $85938.53, \mathrm{R} 2=0.9998$. All quantification results are reported in $\mu \mathrm{g} / \mathrm{mg}$ of extract and correspond to the mean of the contents determined with SRM and SIM, respectively. All analyses were carried out in triplicate and data expressed as mean values \pm standard deviation.

\section{Cell culture}

African green monkey fibroblastoid kidney cells (Vero, ATCC CCL81) were grown as monolayers in Eagle's Minimum Essential Medium (MEM) (Sigma-Aldrich) supplemented with $10 \%$ heat inactivated fetal bovine serum (FBS) (Sigma-Aldrich) and $1 \%$ antibiotic solution (penicillin-streptomycin, Sigma-Aldrich) in humidified 5\% $\mathrm{CO}_{2}$ atmosphere at $37^{\circ} \mathrm{C}$.

\section{Viruses}

Clinical isolates of HSV-1 and HSV-2 were kindly provided by Prof. M. Pistello, University of Pisa, Italy. HSV strains were propagated and titered as reported in Cavalli et al. [24]. A HSV-2 ACV-r was generated as previously described [25].

\section{Viability assay}

Cell viability was measured using an MTS assay as described in Donalisio et al. [25]. The $50 \%$ cytotoxic concentrations ( $\left.\mathrm{CC}_{50}\right)$ and the $95 \%$ confidence intervals were determined using Prism software (Graph-Pad Software).

\section{Virus plaque reduction assay}

Antiviral activity of extracts and pure compounds was determined by viral plaque reduction as reported in Cagno et al. [26]. Acyclovir was tested in parallel as a reference. Results are reported as percentages of viral plaques in comparison to controls for each concentration challenged. The concentration of extracts and pure compounds that reduced viral infectivity by $50 \%$ (half maximal effective concentration, $\mathrm{EC}_{50}$ ) and concentrations that reduced viral infectivity by $90 \%$ (effective concentration-90, $\mathrm{EC}_{90}$ ) were calculated by the Prism program to fit a variable slope-sigmoidal doseresponse curve. The results reported are for 3 experiments performed in duplicate. The $\mathrm{SI}$ was calculated by dividing the $\mathrm{CC}_{50}$ by the $\mathrm{EC}_{50}$ value.

\section{Virus inactivation assay}

Extracts and pure compounds were incubated with HSV-2 $\left(1 \times 10^{5} \mathrm{PFU}\right)$ at concentrations corresponding to $\mathrm{EC}_{90}$ values $(\mu \mathrm{g} /$ $\mathrm{mL}$ ) as obtained in the viral plaque reduction assay. The mixtures were incubated for $0 \mathrm{~h}$ at $37^{\circ} \mathrm{C}$, and for $2 \mathrm{~h}$ at $4^{\circ} \mathrm{C}$ and $37^{\circ} \mathrm{C}$. Dilutions from both treated- and untreated-HSV-2 aliquots were titrated to non-inhibitory concentrations. Viral infectivity was determined microscopically by PFU quantification. Viral titers were reported as PFU per milliliter, and compared.

\section{Time-addition assay}

Serial dilutions of extracts and pure compounds were added to cells: $2 \mathrm{~h}$ before infection, during infection, or post-infection. After the incubation time, viral plaques were counted.

\section{Attachment assay}

The attachment assay was performed as reported in Cagno et al. with several modifications [26]. After infection, unpenetrated HSV-2 virions were inactivated with acidic glycine $(0.1 \mathrm{M}$ glycine, $0.14 \mathrm{M} \mathrm{NaCl}, \mathrm{pH} 3$ ) for $1 \mathrm{~min}$ at room temperature.

\section{Entry assay}

The entry assay was performed as reported in Cagno et al. [26]. The virus was adsorbed for $2 \mathrm{~h}$ at $4{ }^{\circ} \mathrm{C}$ on cells. After 3 washes to remove unbound virus, cells were treated with extract or pure compound for $3 \mathrm{~h}$ at $37^{\circ} \mathrm{C}$. Unpenetrated viruses were inactivated with acidic glycine.

\section{Post entry assay}

Pre-chilled Vero cells were infected with HSV-2 (MOI 0.005) for $2 \mathrm{~h}$ at $+4{ }^{\circ} \mathrm{C}$. After 2 washes, fresh $2 \%$ FBS MEM was added, and the monolayers were moved to $37^{\circ} \mathrm{C}$ to allow virus internalization. Unpenetrated HSV-2 virions were inactivated with acidic glycine; cells were then washed with PBS and pure compounds at concentrations corresponding to $\mathrm{EC}_{90}$ values $(\mu \mathrm{g} / \mathrm{mL})$ were added at 0,1 , 2, 3, 4, 6, and 16 hpi in MEM 2\% FBS, 1.2\% methylcellulose, and incubated at $37^{\circ} \mathrm{C}$ for $24 \mathrm{~h}$.

\section{Virus yield reduction assay}

The assay was performed as reported in Cagno et al. [26]. Cells were treated with compounds, infected in presence of compounds, and incubated until control cultures displayed extensive cytopathology. Supernatants and cells were harvested, and cellfree virus infectivity titers were determined.

\section{Statistical analysis}

Data were analyzed using Student's t-test, ANOVA analysis of variance, or F-test, as reported in the legends of tables and figures, on GraphPad Prism version 5.00 software. Significance was reported for $p$-value $<0.05$. The Student's t-test was used to compare HSV-2 titers in virus inactivation assays; analysis of variance followed by Bonferroni multiple comparison test was used to compare HSV-2 titers in virus yield reduction assays and to compare the percentages of plaque area in the post-treatment assay.

\section{Supporting information}

UV spectrum, mass spectrum, and PIS analysis of the main peak in the extract (Fig. 1S); evaluation of inactivation of HSV-2 particles by apigenin and luteolin (Fig. 2S); HSV-2 attachment and entry assays for apigenin and luteolin (Fig. 3S); schematic representation of the extraction procedure adopted for $A$. tortuosum leaves and tubers (Fig. 4S); and SRM profiles of luteolin and apigenin (Fig. 5S) are available as Supporting Information. 


\section{Acknowledgements}

This work was supported by a donation by Silvana Legnani to D. L.

\section{Conflict of Interest}

The authors declare that they have no conflict of interest.

\section{References}

[1] Centers for Disease Control and Prevention. Genital herpes. Available at https://www.cdc.gov/std/herpes/. Accessed July 3, 2019

[2] Corey L, Wald A. Genital Herpes. In: Holmes KK, Sparling FP, Stamm WE, Piot P, Wasserheit JN, Corey L, Cohen MS, Watts DH, eds. Sexually transmitted Diseases. 4th ed. New York: McGraw-Hill; 2008: 399-437

[3] Centers for Disease Control and Prevention. Sexually Transmitted Diseases Treatment Guidelines. 2015. Available at https://www.cdc.gov/ mmwr/preview/mmwrhtml/rr6403a1.htm. Accessed July 15, 2019

[4] Brunnemann AK, Hoffmann A, Deinhardt-Emmer S, Nagel CH, Rose R, Fickenscher $\mathrm{H}$, Sauerbrei A, Krumbholz A. Relevance of non-synonymous thymidine kinase mutations for antiviral resistance of recombinant herpes simplex virus type 2 strains. Antiviral Res 2018; 152: 53-57

[5] Lembo D, Donalisio M, Civra A, Argenziano M, Cavalli R. Nanomedicine formulations for the delivery of antiviral drugs: a promising solution for the treatment of viral infections. Expert Opin Drug Deliv 2018; 15: $93-$ 114

[6] Akram M, Tahir IM, Shah SMA, Mahmood Z, Altaf A, Ahmad K, Munir N, Daniyal M, Nasir S, Mehboob H. Antiviral potential of medicinal plants against HIV, HSV, influenza, hepatitis, and coxsackievirus: a systematic review. Phytother Res 2018; 32: 811-822

[7] Silva-Mares D, Torres-López E, Rivas-Galindo VM. Antiherpetic plants: a review of active extracts, isolated compounds, and bioassays. Nat Prod Commun 2016; 11: 557-566

[8] Pragada PM, Rao DS, Venkaiah M. Study of some ethnomedicinal plants for treatment of dysentery of North Coastal Andhra Pradesh, India. Int J Biosci 2012; 2: 18-24

[9] Dhuna V, Bains JS, Kamboj SS, Singh J, Kamboj S, Saxena AK. Purification and characterization of a lectin from Arisaema tortuosum Schott having in-vitro anticancer activity against human cancer cell lines. J Biochem Mol Biol 2005; 38: 526-532

[10] Nile SH, Park SW. HPTLC analysis, antioxidant, anti-inflammatory and antiproliferative activities of Arisaema tortuosum tuber extract. Pharm Biol 2014; 52: 221-227

[11] Choudhary K, Singh M, Pillai U. Ethnobotanical survey of Rajasthan an update. Am-Euras J Bot 2008; 1: 38-45

[12] Sharma PP, Majumdar AM. Traditional knowledge of plants from Toranmal Plateau of Maharashtra. Indian J Tradit Know 2003; 2: 292-296
[13] Verma H, Lal VK, Pant KK, Soni N. A ethnomedicinal review on Arisaema tortuosum. Int J Adv Pharm Biol Chem 2012; 1: 176-179

[14] Azam S, Saqib MS, Zar F, Ahmad B, Khan I, Zeb Z, Khan I. Antibacterial, antifungal, phytotoxic, antioxidant and hemagglutination activities of organic fractions of Arisaema tortuosum. Pak J Pharm Sci 2016; 29: 991-997

[15] Kaur M, Singh K, Rup PJ, Saxena AK, Khan RH, Ashraf MT, Kamboj SS, Singh J. A tuber lectin from Arisaema helleborifolium Schott with anti-insect activity against melon fruit fly, Bactrocera cucurbitae (Coquillett) and anti-cancer effect on human cancer cell lines. Arch Biochem Biophys 2006; 445: 156-165

[16] Kant K, Lal UR, Kumar A, Ghosh M. A merged molecular docking, ADME-T and dynamics approaches towards the genus of Arisaema as herpes simplex virus type 1 and type 2 inhibitors. Comput Biol Chem 2019; 78: 217-226

[17] Marengo A, Maxia A, Sanna C, Bertea CM, Bicchi C, Ballero M, Cagliero C, Rubiolo P. Characterization of four wild edible Carduus species from the Mediterranean region via phytochemical and biomolecular analyses. Food Res Int 2017; 100: 822-831

[18] Yang Z, Nakabayashi R, Okazaki Y, Mori T, Takamatsu S, Kitanaka S, Kikuchi J, Saito K. Toward better annotation in plant metabolomics: isolation and structure elucidation of 36 specialized metabolites from Oryza sativa (rice) by using MS/MS and NMR analyses. Metabolomics Off J Metabolomic Soc 2014; 10: 543-555

[19] Du SS, Lei N, Xu YC, Wei LX. Study on flavonoids of Arisaema erubescens. J Chin Pharm Sci 2005; 40: 1457-1459

[20] Chiang LC, Ng LT, Cheng PW, Chiang W, Lin CC. Antiviral activities of extracts and selected pure constituents of Ocimum basilicum. Clin Exp Pharmacol Physiol 2005; 32: 811-816

[21] Visintini Jaime MF, Redko F, Muschietti LV, Campos RH, Martino VS, Cavallaro LV. In vitro antiviral activity of plant extracts from Asteraceae medicinal plants. Virol J 2013; 10: 245

[22] Behbahani M, Zadeh MS, Mohabatkar H. Evaluation of antiherpetic activity of crude extract and fractions of Avicenna marina, in vitro. Antiviral Res 2013; 97: 376-380

[23] Ojha D, Das R, Sobia P, Dwivedi V, Ghosh S, Samanta A, Chattopadhyay D. Pedilanthus tithymaloides inhibits HSV infection by modulating NF-KB signaling. PLoS One 2015; 10: e0139338

[24] Cavalli R, Donalisio M, Bisazza A, Civra A, Ranucci E, Ferruti P, Lembo D. Enhanced antiviral activity of acyclovir loaded into nanoparticles. Methods Enzymol 2012; 509: 1-19

[25] Donalisio M, Nana HM, Ngane RAN, Gatsing D, Tchinda AT, Rovito R, Cagno V, Cagliero C, Boyom FF, Rubiolo P, Bicchi C, Lembo D. In vitro anti-Herpes simplex virus activity of crude extract of the roots of Nauclea latifolia Smith (Rubiaceae). BMC Complement Altern Med 2013; 13: 266

[26] Cagno V, Donalisio M, Civra A, Cagliero C, Rubiolo P, Lembo D. In vitro evaluation of the antiviral properties of Shilajit and investigation of its mechanisms of action. J Ethnopharmacol 2015; 166: 129-134 